\title{
STRATEGI PENGEMBANGAN USAHA KONVEKSI PADA ETIK KONVEKSI DI LAMPUNG TENGAH.
}

\author{
OKTAVIANUR ${ }^{1}$ \\ MILASURYAS YUCIA ${ }^{2}$ \\ Program Studi Manajemen Fakultas Ekonomi Dan Bisnis \\ Universitas Bandar Lampung \\ Email: Oktavianur@ubl.ac.id; Milasuryasyucia01@gmail.com
}

\begin{abstract}
This research was done on small medium enterprises that produce convection in the district of Lampung Tengah. Convection Etik section is a business development in offering many various types of outfits which are needed by the comunity. This kind of business convection is included in Home Industry part that is located on Bandar Sakti, Lampung tengah. It is planning in providing many different kinds of clothes which are varied from school uniform until work outfits. It will also provide many various kinds of fabric clothes, printing clothes, and embroidered. It also believes that in tailoring matters it can compete with others garment section that are owned by others in order to satisfy the costumers and to attract many new costumers. Data used is primary and secondary data. Primary data obtained through field surveys, while secondary data obtained from various publication sources. Method of analysis used is descriptive approach. By using strategic of business, Etik convection section is worth to develop.
\end{abstract}

Keyword: Business Strategy, development Convection

\begin{abstract}
ABSTRAK
Penelitian ini telah di lakukan pada industry kecil konveksi di Lampung Tengah. Etik Konveksi merupakan pengembangan usaha yang menawarkan berbagai jenis pakaian yang di butuhkan masyarakat. Usaha Konveksi termasuk Home Industry yang berlokasi di Bandar Sakti, Lampung Tengah. Etik konveksi menyediakan berbagai jenis bahan pakaian di mulai dari pakaian sekolah hingga pakaian kerja. Etik konveksi juga menyediakan berbagai macam jenis kualitas bahan, sablon dan bordiran. Etik konveksi dalam segi penjahitan juga memiliki kualitas bahan jahitan yang mampu bersaing dengan konveksi lainnya sehingga dapat membuat pelanggan tertarik untuk datang. Penelitian ini menggunakan data primer dan sekunder. Data primer di peroleh dari survey lapangan,sedangkan data sekunder diperoleh dari berbagai publikasi. Metode analisis yang digunakan adalah pendekatan deskriptif. Dengan menggunakan strategi usaha ini, usaha etik konveksi merupakan usaha yang layak untuk dikembangkan.
\end{abstract}

\section{Kata kunci : Strategi Bisnis, Perkembangan Konveksi}




\section{A. PENDAHULUAN}

Dalam perekonomian Indonesia industri kecil dan menengah memiliki peran sangat besar terhadap perekonomian. Konveksi ini juga sering di sebut industri rumahan. Banyak kebutuhan bagi kehidupan manusia baik dari makanan dan minuman namun masyarakat juga membutuhkan pakaian baik yang dikenakan sehari-hari atau kebutuhan kusus lainnya. Pada umumnya pengusaha konveksi mendapatkan pesanan dan jumlah besar pada momen-momen tertentu saja,seperti menjelang lebaran, dan pergantian tahunan ajaran baru atau eventevent yang lainnya.Dalam hal ini memudahkan pebisnis untuk menjalankan sebuah bisnis konveksi agar tetap lancar dan semakin berkembang usahanya. Konveksi (pakaian jadi), di khususkan untuk pelajar, mahasiswa dan karyawan atau pegawai perusahaan.

Dalam perkembangan kemajuan perkembangan ilmu pengetahuan dan teknologi, masyarakat pada zaman sekarang banyak mengikuti baik sebuah organisasi atau pun komunitas. Maka dalam ini masyarakat membutuhkan suatu identitas agar terlihat lebih kompak dan mudah dikenali masyarakat luas. Karena disebuah komunitas contohnya ,jika tidak ada suatu identitas maka komunitas satu dan lainnya sulit untuk saling memperkenalkan komunitasnya selain itu seperti halnya contoh dari identitas gojek dan grab, mereka perlu adanya identitas seperti jaket agar mudah di kenali oleh penumpangnya. Dari pemikiran inilah mucul ide bisnis dari Ibu Etik. Beliau melihat peluang bisnis yang dianggap nya bisnis ini menjanjkan untuk prospek usaha nya kedepan. Namun dalam memulai usaha dalam bidang apa pun, maka yang pertama kali harus di lakukan oleh pebisnis, ia harus mengetahui bagaimana peluang pasar dan siapa saja yang menjadi target pemasaran.

Selain menghasilkan keuntungan yang tinggi, pakaian adalah salah satu yang di butuhkan untuk masyarakat. Baik dari bayi hingga dewasa bahkan orang tua semua membutuhkan pakaian dalam keidupan sehari-hari. Menekuni bisnis konveksi ini sama seperti halnya menekuni bisnis kuliner, harus sama-sama cermat dalam memanfaatkan peluang pasar. Bisnis ini lebih memperlihatkan kualitas bahan dan dalam pengerjaannya. Jika kualitas produksi ini sesuai dengan konsumen, maka kemungkinan besar permintaan akan terus meningkat. Namun memang tidak menjamim seratus persen ,karena ada juga konsumen mencari kualitas dan harga yang sesuai dengan dana mereka punya serta mencari tempat yang mudah di jangkau dalam pemesanan.

Menekuni bisnis konveksi ini memerlukan ketekunan serta keulatan dalam menjalankan usaha di bidang konveksi.karena menjadi pokok utama dalam usaha ini adalah kualitas pakaian dan bahan yang di buat. Konveksi ini biasanya permintaan meningkat ketika masuk ajaran baru anak sekolah atau ada kegiatan event besar yang membutuhkan pemesanan baju dengan tema yang sama.namun dalam usaha konveksi ini, pemilik harus mempunyai strategi dan ketrampilan khusus dalam mengembangkan usaha konveksi ini. Karena mengembangkan usaha konveksi ini sangat penting untuk kemajuan perusahaan. Akan tetapi dalam strategi pegembangannya harus melihat kepercayaan konsumen terhadap kepuasan kualitas produk.

Dalam menjalankan usaha ini, selain harus mempunyai modal yang cukup, pemilik juga harus mempunyai jiwa dan mental yang kuat. Karena dalam usaha pastinya tidak selalu berjalan dengan baik. Jika seseorang memilih untuk mendirikan suatu usaha maka harus siap pula dalam menghadapi resiko yang akan terjadi. Kunci membuat suatu usaha ialah niat dan tekat. Karena untuk menghalang berbagai hambatan psikologis rasa malu, takut gagal dan memadamkan perang batin antara berkeinginan dan keraguan adalah langkah pertama yang harus diatasi.Setelah sekiranya beban mental sudah teratasi, maka hal 
berikutnyaadalah masalah operasional.Dalam masalah operasional ini yang harus diperhatikan adalah pertimbangan kemampuan diri, keterampilan yang dimiliki yang menyangkut bidang pekerjaan itu. Contohnya dalam usaha konveksi, paling tidak dibutuhkan orang yang mengerti pola dalam jahitan dan mengerti penggunaan mesin jahit,baik manual maupun tidak manual. Akan tetapi dalam usaha konveksi tidaklah harus ahli membuat suatu pakaian karena untuk langkah awalnya harus mengetahui dan bagaimana cara menjalankan usaha tersebut agar berjalan dengan semestinya. Sementara untuk tenaga kerja bisa di lakukan melalui perekrutan pegawai. Persiapan berikutnya adalah persediaan sarana dan prasarana.

Usaha konveksi sudah cukup banyak di wilayah Lampung Tengah. Dalam hal ini membuat persaingan sesama usaha konveksi semakin ketat. Ini merupakan pendorong bagi mereka yang mempunyai usaha konveksi untuk meningkatkan kualitas produk. Tidak terkecuali Etik konveksi sebagai salah satu penyedia konveksi di lampung tengah juga menyadari pentingnya kualitas pelayanan terhadap konsumen. Etik konveksi adalah salah satu usaha konveksi yang ada di Lampung Tengah. Etik Konveksi ini berdiri sejak 2012 dengan berbagai usaha yang telah di lakukan oleh Etik selaku pemilik konveksi yang tadinya hanya sebagai karyawan konveksi. Namun dalam bidang yang ia tekuni di konveksi membuat ia menjadi salah satu karyawan yang di dapat diperhitungkan keahliannya. Etik adalah seorang yang mempuyai keterampilan lebih di bandingan karyawan lainnya. Ia bisa di sebut tangan kanan sang pemilik konveksi terdahulu. Lokasinya pun dahulu berada di Bandar Jaya Lampung Tengah. Setelah memiliki modal yang cukup serta keterampilan yang ia cukup kuasai, maka ia mengambil keputusan untuk membuka usaha konveksi dan membangun konveksi ia sendiri di Bandar Sakti Lampung Tengah,yang ia beri nama Etik konveksi. Berikut ini akan disajikan daftar produk jual yang disediakan Etik Konveksi di Bandar Sakti Lampung Tengah.

Tabel 1.1

Tabel Daftar Produk Jual Etik Konveksi

\begin{tabular}{|l|l|l|}
\hline Produk & Harga Eceran & Harga Grosir \\
\hline Kaos Olahraga TK & Rp. 60.000 & Rp. 55.000 \\
\hline Kaos Olahraga SD & Rp. 70.000 & Rp. 65.000 \\
\hline Kaos Olahraga SMP & Rp. 80.000 & Rp. 75.000 \\
\hline Kaos Olahraga SLTA & Rp. 90.000 & Rp. 85.000 \\
\hline Kaos Olahraga Umum & Rp. 100.000 & Rp. 95.000 \\
\hline Seragam Sekolah TK & Rp. 65.000 & Rp. 60.000 \\
\hline Seragam Sekolah SD & Rp. 75.000 & Rp.70.000 \\
\hline Seragam Sekolah SMP & Rp. 85.000 & Rp. 80.000 \\
\hline Seragam Sekolah SLTA & Rp. 95.000 & Rp. 90.000 \\
\hline Wearparck & Rp. 150.000 & Rp. 145.000 \\
\hline Topi & Rp. 15.000 & Rp. 10.000 \\
\hline Dasi & Rp. 10.000 & Rp. 5.000 \\
\hline Almamater & Rp. 100.000 & Rp. 95.000 \\
\hline Kemeja Polos & Rp. 90.000 & Rp. 85.000 \\
\hline Kemeja Bordir & Rp. 120.000 & Rp. 115.000 \\
\hline
\end{tabular}

Sumber : Etik Konveksi, 2018 
Dalam menjalankan usaha tersebut sang pemilik memiliki pegawai sebanyak 11 orang yang membantu dalam pembuatan produk kepada para konsumen. Keberani dalam membuka usaha ini Etik konveksi menggunakan aspek ekonomi yang menajadi motivasi tujuan usaha nya. Dalam usaha ini sang pemilik melihat peluang yang cukup menjanjikan karena di lihat dari tahun ketahun pemesan terus meningkat terkhusus pemesanan dari beberapa sekolah di Lampung Tengah. Usaha konveksi ini membutuhkan sebuah target untuk menetapkan jumlah permintaan yang sesuai.

Jumlah permintaan ini sangat mempengaruhi keuntungan yang di dapat serta minat konsumen untuk memesan di Etik konveksi. Keuntungan yang didapat oleh Etik konveksi dapat di lihat dari jumlah yang di pesan bukan di lihat dari jumlah konsumen. Karena jumlah konsumen tidak dapat ditentukan seberapa banyak jumlah permintaan. Maka dari itu dapat di lihat dari seberapa banyak pemesanan bukan seberapa banyak konsumen. Di bawah ini akan disajikan tabel volume penjualan yang disediakan Etik Konveksi bagi konsumennya.

Tabel 1.2

Tabel volume penjualan Etik Konveksi di Lampung Tengah selama berdiri sejak tahun 2012

\begin{tabular}{|c|c|c|}
\hline Persedian & $\begin{array}{c}\text { Jumlah yang } \\
\text { disediakan }\end{array}$ & $\begin{array}{c}\text { Jumlah yang } \\
\text { pernah terjual }\end{array}$ \\
\hline Minimal & 2000 stel & 3000 Stel \\
\hline Maksimal & 4500 stel & 4300 Stel \\
\hline
\end{tabular}

Sumber:Etik Konveksi, 2018

Dari data diatas dapat diketahui volume penjualan yang dapat dilakukan Etik Konveksi ialah untuk permintaan yang menduduki nilai minimal hanya menyediakan 2000 stel pesanan .Sedangkan nilai maksimal, Etik Konveksi hanya menyediakan sebanyak 4500 stel pesanan. Etik Koveksi memiliki target penjualan yang harus dipenuhi setiap bulannya. Target penjualan tersebut dapat dilihat dari jumlah permintaan yang sanggup Etik terima setiap tahunnya. Dapat dilihat dari tabel di atas bahwa jumlah permintaan yang disediakan ialah 4500 stel pesanan namun Etik Konveksi pernah hanya melayani permintaan paling tertinggi sejumlah 4300 stel pesanan, yang artinya Etik konveksi tidak pernah mencapai target.

Keuntungan yang didapat Etik Konveksi dapat dilihat dari jumlah pesanan yang dipesan bukan dilihat dari jumlah konsumen. Karena jumlah konsumen tidak menentukan banyaknya jumlah permintaan Etik Konvesi.Sehingga volume penjualan ditentukan dari seberapa banyak konsumen memesan baju di Etik Konveksi. Jumlah perkembangan pemesanan Etik Konveksi dari lima tahun terakhir dapat dilihat pada tabel dibawah ini :

Tabel 1.3

Tabel data perkembangan pemesanan lima tahun terakhir

\begin{tabular}{|c|c|c|c|}
\hline No & Tahun & $\begin{array}{l}\text { Jumlah } \\
\text { Pesanan }\end{array}$ & $\begin{array}{c}\text { Perkembangan } \\
(\%)\end{array}$ \\
\hline 1 & 2014 & 4.000 stel & - \\
\hline 2 & 2015 & 4.220 stel & $5 \%$ \\
\hline 3 & 2016 & 4.250 stel & $0,7 \%$ \\
\hline 4 & 2017 & 4.260 stel & $0,2 \%$ \\
\hline 5 & 2018 & 4.300 stel & $0,9 \%$ \\
\hline & Imlah & 21.030 stel & \\
\hline \multicolumn{3}{|c|}{ Rata-rata (\%) } & $6,8 \%$ \\
\hline
\end{tabular}

Sumber : Etik Konveksi, 2018

Dalam perhitungan pemesanan yang di alami oleh Etik Konveksi mengalami pasang surut. Jumlah penjualan lima tahun terakhir yang dialami Etik konveksi mengalami pasang surut. Namun perkembangan yang dialami Etik konveksi masih dikatakan stabil, itu terlihat dari jumlah pemesanan pada tabel di atas. Tidak hanya melihat dari lima tahun terakhir, untuk mengetahui perkembangannya setiap tahun kita harus melihat juga perkembangan konveksi ini pada tahun terakhir yaitu dari bulan januari sampai desember tahun 2018. Dari keuntungan itulah, sebuah usaha dapat bertahan.Data di bawah ini ialah data jumlah 
pendapatan Etik konveksi lima tahun terakhir.

Tabel 1.4

Tabel data pendapatan perkembangan lima tahun terakhir

\begin{tabular}{|c|c|c|c|}
\hline No & Tahun & $\begin{array}{c}\text { Jumlah } \\
\text { Pendapatan }\end{array}$ & $\begin{array}{c}\text { Perkembangan } \\
(\%)\end{array}$ \\
\hline 1 & 2014 & 100.000 .000 & - \\
\hline 2 & 2015 & 101.280 .000 & $101 \%$ \\
\hline 3 & 2016 & 102.200 .000 & $102 \%$ \\
\hline 4 & 2017 & 102.240 .000 & $102 \%$ \\
\hline 5 & 2018 & 103.200 .000 & $103 \%$ \\
\hline & umlah & 508.920 .000 & \\
\hline \multicolumn{3}{|c|}{ Rata-rata (\%) } & $408 \%$ \\
\hline
\end{tabular}

Sumber : Etik Konveksi, 2018

Selain mengetahui pendapatan pertahun, selanjutnya dalam menunjang kelancaran produksi di Etik Konveksi maka perlu adanya perlengkapan yang di butuhkan dalam produksi. Di bawah adalah data inventaris kantor yang berada di Etik Konveksi.

Tabel 1.5

Tabel Data Inventaris Kantor Pertahun

\begin{tabular}{|l|l|}
\hline Inventaris Kantor & Kuantitas \\
\hline Benang Obras Gulung & 12 lusin \\
\hline Benang Jahit & 156 Roll \\
\hline Kain Keras & 24 Roll \\
\hline Karet & 12 Roll \\
\hline Jarum jahit & 12 Lusin \\
\hline Kancing & 12 Ball \\
\hline Oli Mesin & 12 Liter \\
\hline Hak(Kaitan) & 24 Kotak \\
\hline Sleting & 120 lusin \\
\hline Mesin Jahit & 1 Mesin \\
\hline Mesin Kancing & 6 Mesin \\
\hline Mesin Obras & 3 Mesin \\
\hline Mesin Gulung & 1 Mesin \\
\hline Mesin Potong & 4 Mesin \\
\hline Operdate ( Nyetrip) & 24 Roll \\
\hline Kapur Pembuatan Pola & 12 pcs \\
\hline
\end{tabular}

Sumber : Etik Konveksi, 2018
Tabel 1.6

Tabel Daftar Alat Tulis Kantor Pertahun

\begin{tabular}{|l|l|}
\hline Alat Tulis Kantor & Kuantitas \\
\hline Buku Kas & 12 Pcs \\
\hline Pena & 2 Kotak \\
\hline Kuitansi & 24 Pcs \\
\hline Kalkulator & 1 Pcs \\
\hline Gunting & 2 Pcs \\
\hline Tinta Print & 30 Pcs \\
\hline Kertas A4 & 8 Rim \\
\hline
\end{tabular}

Sumber : Etik Konveksi, 2018

Dalam pemesanan tidak terus mengalami peningkatan dalam penjualannya. Dikarenakan pemesanan jumlah banyak biasanya di bulan-bulan tertentu. Di bawah ini disajikan tabel jumlah penjualan selama periode tahun 2018.

Tabel 1.7

Tabel Penjualan Etik konveksi di Lampung Tengah 2018

\begin{tabular}{|l|l|c|c|}
\hline No & \multicolumn{1}{|c|}{ Bulan } & $\begin{array}{c}\text { Jumlah } \\
\text { Penjualan }\end{array}$ & $\begin{array}{c}\text { Perkembangan } \\
(\%)\end{array}$ \\
\hline 1 & Januari & 50 stel & - \\
\hline 2 & Februari & 60 stel & $16 \%$ \\
\hline 3 & Maret & 80 stel & $25 \%$ \\
\hline 4 & April & 95 stel & $15 \%$ \\
\hline 5 & Mei & 100 stel & $5 \%$ \\
\hline 6 & Juni & 330 stel & $69 \%$ \\
\hline 7 & Juli & 200 stel & $-10 \%$ \\
\hline 8 & Agustus & 150 stel & $-33 \%$ \\
\hline 9 & September & 155 stel & $3 \%$ \\
\hline 10 & Oktober & 100 stel & $-55 \%$ \\
\hline 11 & November & 110 stel & $9 \%$ \\
\hline 12 & Desember & 115 stel & $4 \%$ \\
\hline Jumlah & 1555 stel & $48 \%$ \\
\hline \multicolumn{2}{|l|}{ Rata-Rata (\%) } & \\
\hline
\end{tabular}

Sumber : Etik Konveksi, 2018

Data yang terdapatdi atas berasal dari pemesanan Etik Konveksi dalam setahun terakhir. Jumlah pemesanan konveksi bukan per konsumen. Perkembangan yang terjadi pada jumlah pemesanan konveksi ini ada yang mengalami penurunan dan kenaikan jumlah pemesanan .Itu dikarenakan jumlah 
pemesanan yang berbeda tiap bulan dan tiap tahun. Penjualana konveksi meningkat terjadi ketika memasuki tahun ajaran baru sekolah. Namun pada bulan-bulan biasa tidak banyak pesanan bahkan teradang sebulan atau dua bulan tidak dapat pesanan. jumlah pendapatan yang didapat Etik
Konveksi ini yang menjadi faktor yang harus diperhatikan karena dari hal itu kita dapat mengetahui keuntungan yang didapat. Dari keuntungan itulah, sebuah usaha dapat bertahan. Data di bawah ini ialah data jumlah pendapatan Etik konveksi selama periode 2018.

Tabel 1.8

Tabel jumlah pendapatan Etik Konveksi selama tahun 2018

\begin{tabular}{|l|l|l|c|}
\hline No & \multicolumn{1}{|c|}{ Bulan } & \multicolumn{1}{|c|}{ Pendapatan } & $\begin{array}{c}\text { Perkembangan } \\
(\%)\end{array}$ \\
\hline 1 & Januari & Rp. 8.500 .000 & - \\
\hline 2 & Februari & Rp. 10.200 .000 & $10 \%$ \\
\hline 3 & Maret & Rp. 13.600 .000 & $13 \%$ \\
\hline 4 & April & Rp. 16.150 .000 & $16 \%$ \\
\hline 5 & Mei & Rp. 17.000 .000 & $16 \%$ \\
\hline 6 & Juni & Rp. 56.100 .000 & $56 \%$ \\
\hline 7 & Juli & Rp. 34.000 .000 & $33 \%$ \\
\hline 8 & Agustus & Rp. 25.500 .000 & $25 \%$ \\
\hline 9 & September & Rp. 26.350 .000 & $26 \%$ \\
\hline 10 & Oktober & Rp. 17.000 .000 & $16 \%$ \\
\hline 11 & November & Rp. 18.700 .000 & $18 \%$ \\
\hline 12 & Desember & Rp. 19.550 .000 & $19 \%$ \\
\hline Jumlah & Rp. 262.650 .000 & $248 \%$ \\
\hline Rata-rata $(\%)$ & &
\end{tabular}

Sumber : Etik Konveksi, 2018

Dari tabel 1.7 di atas dapat diketahui bahwa jumlah pendapatan Etik konveksi selama bulan januari sampai desember 2018 berfluktuasi tetapi kenaikan dan penurunan pendapatan yang diterima Etik Konveksi cenderung signifikan. Hal ini menyebabkan tidak selalu ada pemesanan di setiap bulannya melihat tahun ajaran baru untuk sekolah di lihat dari bulan juni. Namun adanya konveksi ini memberikan keuntungan untuk masyrakat luas. Dapat dilihat dari grafik di bawah ini yang merupakan gambaran dari tabel di atas.

\section{Grafik 1.1 jumlah perkembangan pendapatan konveksi selama 2018}

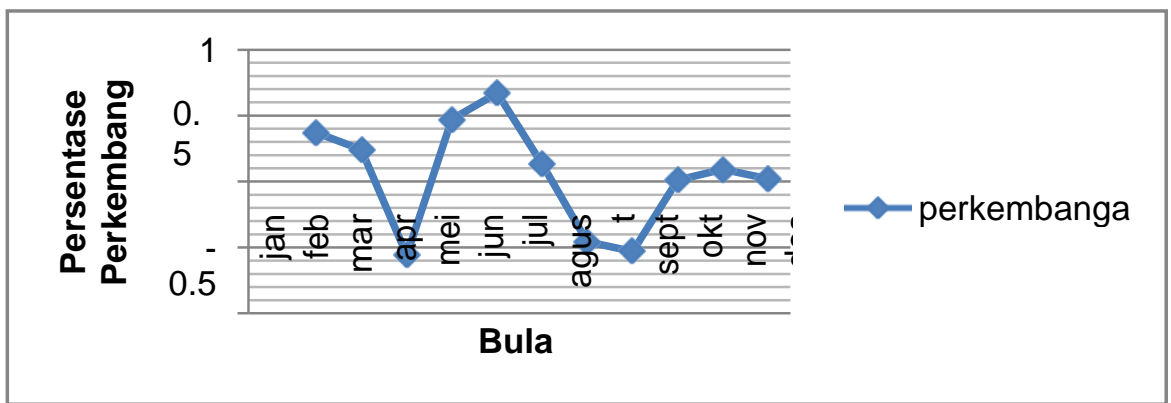

Sumber : Data diolah (2018) 
Tabel di bawah ini akan menerangkan target pencapaian penjualan konveksi.

Tabel 1.9

Tabel Target Pencapaian Penjualan Konveksi selama lima tahun terakhir

\begin{tabular}{|c|c|c|}
\hline $\begin{array}{c}\text { Target } \\
\text { Pendapatan }\end{array}$ & Realisasi & $\begin{array}{c}\text { Target yang } \\
\text { tercapai (\%) }\end{array}$ \\
\hline Rp. 300.000.000 & Rp. 262.650.000 & $87,55 \%$ \\
\hline
\end{tabular}

Dari tabel di atas dapat diketahui bahwa untuk target penjualan yang seharusnya dicapai Etik Konveksi tidak terpenuhi dengan baik. Etik Konveksi hanya memenuhi $87,55 \%$ dari $100 \%$.

Etik sebagai pemilik konveksi di tuntut untuk menciptakan ide yang kreatif dan inovasi agar dapat menghadapi tingginya persaingan pasar dan dapat memenangkan persaingan. Adapun strategi yang dilakukan oleh Etik konveksi selama ini dalam ketatnya persaingan tersebut ialah dengan memberikan pelayanan yang baik, kualitas bahan yang baik, pengerjaan pembuatan produk rapih, harga bisa di bicarakan sesuai kualitas bahan dan kerumitan dalam pengerjaannya, dalam pemesanan bisa tanpa dp jika itu sebuah instansi/perusahaan dan sekolah.

Strategi yang sudah di lakukan tidak menjamin usaha Etik Konveksi selalu ramai pemesanan, hal ini di sebabkan karena banyak pesaing konveksi lainnya yang lokasinya lebih mudah terjangkau dan melakukan berbagai macam strategi juga. Berdasarkan pengamatan, pemesanan yang diterima Etik Konveksi relatif (rata-rata). Dalam menghadapi kerugian Etik Konveksi yang disebabkan oleh pengorganisasian serta modal, maka Etik Konveki harus memiliki strategi baru dalam pengembangan usahanya agar pemesanan semakin meningkat.

\section{B. METODE PENELITIAN}

Dalam penelitian ini peneliti menggunakan teknik penelitian sebagai berikut: a. Penelitian kepustakaan (library research)

Penelitian kepustakaan dilakukan dengan cara mempelajari literaturliteratur yang berkaitan dengan penelitian mengenai strategi bisnis.

b. Penelitian lapangan (field research)

Yaitu pengumpulan data serta informasi dengan cara melakukan pengamatan langsung ke tempat objek penelitian

Dalam penelitian ini peneliti menggunakan teknik pengumpulan data berupa metode analisis kualitatif, yaitu metode yang digunakan untuk menganalisis data dengan menggunakan penalaran dan penelaahan dengan berpedoman pada pendekatan teoritis serta teknik pengumpulan data adalah : observasi, wawancara, dokumentasi dan kuisioner.

Kalaupun ada data berupa angkaangka sifat analisis hanya terbatas pada pemberian informasi, menilai atau mengevaluasi data angka tersebut kemudian melakukan penafsiran dan menyimpulkan. Adapun alat analisis yang digunakan dalam penelitian ini yaitu Analisis SWOT (Strengths, Weakness, Opportunity, And Threats).

Metode kerja analisis SWOT guna menentukan kekuatan, kelemahan, peluang, dan ancaman pada Etik Konveksi adalah sebagai berikut :

a) Mengisi kolom pernyataan dengan memberi tanda silang (X) pada kolom yang sudah disediakan.

b) Mengidentifikasi faktor internal yang menjadi kekuatan dan kelemahan bagi perusahaan Etik Konveksi serta faktor eksternal yang menjadi peluang dan ancaman bagi Etik Konveksi.

c) Setelah faktor-faktor teridentifikasi maka dilakukan pembobotan serta ranking. Bobot dihitung 0.0 (tidak penting) sampai 1.0 (sangat penting)

d) Setiap pertanyaan diberikan nilai menurut tingkat kepentingannya oleh pemilik berdasarkan kondisi lingkungannya baik internal maupun 
eksternal, dengan asumsi menggunakan skala likert (Freddy Rangkuti 2014) :

$\mathrm{A}=$ Kurang Penting

$\mathrm{B}=$ Cukup Penting

$\mathrm{C}=$ Penting

$\mathrm{D}=$ Sangat Penting e) Pada setiap kolom ditetapkan nilai antara lain:
$\mathrm{A}=1$
$\mathrm{B}=2$
$\mathrm{C}=3$
$\mathrm{D}=4$

Moleong (2007) mengemukakan bahwa pelaksanaan penelitian ada empat tahap yaitu sebagai berikut :

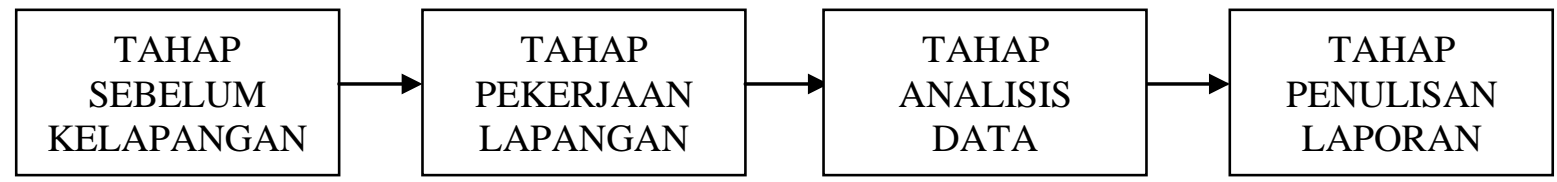

\section{PEMBAHASAN}

Etik konveksi ini ialah usaha yang ada di Lampung Tengah tepatnya di Bandar Sakti. Konveksi ini telah berdiri sejak tahun 2012 dengan berbagai macam usaha baik dalam promosi maupun penjualannya.

Pada awal nya pemilik konveksi ini membuka usaha dari pengalamannya ia sebagai karyawan konveksi di tempat ia kerja sebelumnya. Pertama kali konveksi yang ia dirikan ini hanya membuat baju kaos olahraga pelajar dan baju seragam pelajar. Setelah usaha nya semakin dikenal dan banyaknya permintaan menjahit di etik konveksi ini dan ia diberi kepercayaan atas hasil jahitan yang membuat konsumen puas atas pelayanannya maka pada tahun 2012 ia mengambil alih untuk meneruskan usaha konveksi ini yang sebelumnya konveksi ini berada di Bandar Jaya.

Etik konveksi ini belum mempunyai cabang, ia hanya mempunyai satu konveksi di Lampung Tengah. Namun ia sudah memiliki pelanggan tetap yang setiap tahunnya memesan di konveksi ini. Berikut macam-macam produk yang di jual oleh etik konveksi : Kaos olahraga (SD, SMP, SLTA, UMUM), seragam (SD, SMP, SLTA),

kemeja polos, kemeja bordir, almamater, wearpark dasi, topi. Etik konveksi buka pemesanan mulai pukul 07.00 WIB sampai dengan pukul 21.00 WIB.
Adapun hasil perbandingan unsurunsur faktor internal dan eksternal usaha etik konveksi dapat dilihat pada Tabel-tabel di bawah ini :

Tabel Hasil Untuk Faktor Internal Etik Konveksi di Lampung Tengah

\begin{tabular}{|l|l|c|l|}
\hline No & $\begin{array}{l}\text { Unsur-unsur } \\
\text { Faktor Internal }\end{array}$ & Nilai & $\begin{array}{l}\text { Strength/ } \\
\text { Weakness }\end{array}$ \\
\hline 1. & $\begin{array}{l}\text { Macam-macam } \\
\text { jenis produk }\end{array}$ & 4 & Strenght \\
\hline 2. & $\begin{array}{l}\text { Persediaan bahan } \\
\text { baku }\end{array}$ & 3 & Weakness \\
\hline 3. & $\begin{array}{l}\text { Kemudahan } \\
\text { mendapatkan } \\
\text { bahan baku }\end{array}$ & 4 & Stenght \\
\hline 4. & Harga terjangkau & 4 & Strenght \\
\hline 4. & $\begin{array}{l}\text { Perbandingan } \\
\text { harga dengan } \\
\text { pesaing }\end{array}$ & 2 & Weakness \\
\hline 6. & $\begin{array}{l}\text { Promosi } \\
\text { menggunakan } \\
\text { iklan }\end{array}$ & 1 & Weakness \\
\hline 7. & Lokasi usaha & 4 & Strenght \\
\hline 8. & $\begin{array}{l}\text { Tempat } \\
\text { yang luas }\end{array}$ & 2 & Weakness \\
\hline 9. & Fasilitas produksi & 4 & Strenght \\
\hline 10. & Pelayanan & 3 & Weakness \\
\hline 11. & Jumlah pekerja & 4 & Strenght \\
\hline 12. & $\begin{array}{l}\text { Tingkat } \\
\text { kepercayaan } \\
\text { terhadap pekerja }\end{array}$ & & \\
\hline Sunger: Datadiolah & & \\
\hline
\end{tabular}

Sumber : Data diolah (2019) 
Pada tabel tersebut dapat kita lihat hasil tabel internal Etik Konveksi yang dapat menjadi kekuatan dan kelemahan. Berikut ini akan ditampilkan hasil tabel eksternal Etik Konveksi yang akan menjadi peluang atau ancaman.

Tabel Hasil Untuk Faktor Eksternal Etik Konveksi di Lampung Tengah

\begin{tabular}{|l|l|c|l|}
\hline No & Unsur-unsur Faktor Eksternal & Nilai & Opportunity/Threat \\
\hline 1. & Memiliki konsumen yang setia & 4 & Opportunity \\
\hline 2. & Kualitas bahan baku sesuai pesanan & 3 & Opportunity \\
\hline 3. & Adanya pesaing & 1 & Threat \\
\hline 4. & Memiliki kesamaan produk dengan pesaing & 2 & Threat \\
\hline 5. & Harga yang ditawarkan oleh pesaing & 1 & Threat \\
\hline 6. & Usaha sesuai peraturan pemerintah & 3 & Opportunity \\
\hline
\end{tabular}

Sumber : data diolah (2019)

\section{KESIMPULAN DAN SARAN}

\section{Kesimpulan}

Berdasarkan penelitian yang telah dilakukan maka dapat dihasilkan beberapa kesimpulan untuk Etik Konveksi diantaranya:

Strenght Opportunity (SO) yang dapat dilakukan yaitu :

1. Meningkatkan kualitas produk untuk memenuhi harapan masyarakat.

2. Meningkatkan kerjasama team guna pengerjaan agar lebih cepat.

3. Meningkatkan kualitas produk

4. Memberikan pelatihan khusus kepada pegawai agar dapat mempermudah proses dalam pekerjaan.

5. Menjaga kepercayaan konsumen dan pekerja

Weakness Opportunity (WO) yang dapat digunakan yaitu :

1. Menambah inovasi produk.

2. Mencari mitra usaha penyedia bahan baku yang mudah untuk diajak kerjasama.

3. Menambah pekerja yang handal dan terpercaya

4. Mengatur keuangan dengan baik agar pengeluaran dan pemasukan afektif dan efisien
5. Memberikan sosialisasi dan pemahaman terkait pekerjaan agar seluruh pegawai dapat bekerja dengan baik.

Strengt Threat (ST) yang dapat dilakukan yaitu:

1. Mengatasi ancaman dengan meningkatkan kualitas pekerja dalam pengerjaan produksi konveksi. Pembelajaran

2. Meningkatkan kualitas barang hasil yang lebih baik dari pesaing.

3. Perekrutan pegawai agar pengerjaan dapat lebih cepat dan dapat menerima pesanan di luar kapasitas perusahaan.

Weakness Threat (WT) yang dapat dilakukan yaitu:

1. Melakukan inovasi produk guna meningkatkan kualitas produk sehingga dapat memenuhi kebutuhan konsumen

2. Perusahaan harus lebih memperhatikan harga pesaing yang ditawarkan untuk konsumen

3. Perusahaan lebih baik menggunakan promosi agar usaha konveksi ini lebih dikenal masyarakat luas.

Berdasarkan diagram cartesius analisis SWOT Etik Konveksi berada dikuadran I. Pada kuadran ini,Etik Konveksi memiliki peluang dan kekuatan sehingga 
dapat memanfaatkan peluang yang ada. Strategi yang diterapkan dalam kondisi ini adalah mendukung kebijakan pertumbuhan yang agresif (Growth Oriented Strategy), yaitu strategi generik (strategi pertumbuhan) menurut Hubeis dan Najib (2014).

\section{Saran}

Berdasarkan Hasil analisis SWOT pada Etik konveksi, diperoleh berbagai macam strategi yang dapat dilakukan untuk perkembangan perusahaan. Dalam menerapkan strategi-strategi tersebut sebaiknya etik konveksi memperhatikan :

1. Memanfaatkan peluang banyaknya pelanggan yang setia dengan cara meningkatkan kualitas produksi

2. Memberikan inovasi - inovasi baru dalam produksinya dan memberikan pelayanan lebih baik lagi agar pelanggan tetap setia tidak beralih ke pesaing lain.

3. Melakukan promosi agar usaha konveksi ini dapat dikenal masyarakat luas

4. Memperluas tempat usaha

\section{DAFTAR PUSTAKA}

A.F . Stoner. 2006. Manajemen Sumber Daya Manusia. Jakarta: Bumi Aksara.

David.F. R. 2006. Manajemen StrategiKonsep-Konsep, Edisisembilan. PT. Indeks,

Jakarta Hanifa Rifati. 2017. Analisis Strategi Pengembangan Usaha Distro Legacy Brand Store Metro, Lampung. Metro.

Hunger, David. J. 2003. Manajemen Strategis. Yogyakarta. Penerbit Andi

Hariadi. 2005. Strategi Manajemen. Bayu media Publishing, Jakarta

Hasibuan, Malayu S.P. 2016. Manajemen Sumber Daya Manusia. Edisi. Revisi. Jakarta: Penerbit PT Bumi Aksara.

Hubeis, Musa dan Najib,Mukhamad (2014).

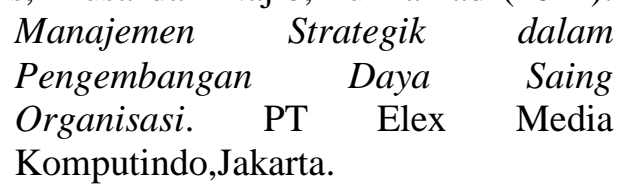

Indra, Rendy S. 2017. Analisis Strategi Pengembangan Bisnis PT. Patrinsaka. Surabaya

Meleong, Lexy J. 2007. Metode Penelitian Kualitatif. Bandung: Remaja Rosdakarya Bandung

Prof. Dr. Sondang P. Siagian, MPA, 2016. Manajemen Strategik. PT. Bumi Aksara.

Rangkuti, Freddy. 2006. Teknik Mengukur dan Strategi Meningktakan Kepuasan Pelanggan. Jakarta: Penerbit PT Gramedia Pustaka Utama.

Rangkuti, Freddy. 2014. Analisis SWOT Teknik Membedah Kasus Bisnis.

Jakarta. PT. Gramedia Pustaka Utama. Sugiyono. 2008. Metode Penelitian Kombinasi (Mixed Methods). Bandung: Alfabeta.

Terry, George: Leslie W. Rue. 2010. Dasardasar Manajemen. Cetakan kesebelas. Jakarta. PT. Bumi Aksara.

https://ahsaniuj.wordpress.com/2015/04/05/d efinisi-manajemen-menurut-para-ahli/ 